\author{
Article type : Research Article \\ Date Received :03/10/2021 \\ Date Accepted : 22/10/2021 \\ Date published : 01/12/2021 \\ : www.minarjournal.com \\ http://dx.doi.org/10.47832/2717-8234.4-3.1
}

\title{
THE IMPACT OF THE TRUST FACTOR ON EMPLOYEES' PERFORMANCE IN IRAQI PUBLIC AND PRIVATE SECTOR PROJECTS
}

\author{
Nooralhuda M. AZIZE 1
}

\begin{abstract}
Construction companies always attempt to improve their productivity. Trust is the best way to achieve its goal, because it is a very useful way to improve employees and organizational productivity as well as effective strategic plans implementation. In this research, we examine how a trust climate provides a favorable environment for the performance of employees and the development of organizational efficiency and effectiveness. Also, this study has analyzed the trust effects on the performance of employees. The population of this study is private and public sector projects from which a sample of (26) projects in Iraq are chosen. Data are collected and the test of the model is on (140) respondents (project team members and workers) of construction companies in Iraq. The evaluation the concepts data is analyzed by using descriptive statistics, correlation, and regression tests. Hypothesis results indicate a positive relationship between the independent variable and dependent variable. Lastly, research limitations, recommendations for future research, and conclusions are discussed in details.
\end{abstract}

Keywords: Trust, Employees' Performance, Public and Private Sector Projects. Iraq.

\footnotetext{
${ }^{1}$ Thi-Qar University, Iraq, Noralhudamohammed212@utq.edu.iq,https://orcid.org/0000-0001-9326-5291
} 


\section{Introduction}

In the last few decades, the emergence of project management has led to a paradigm shift. There are multiple driving forces including changes in the production and IT sectors, changes in the development of human capital, and the working patterns. These changes have caused a shift between a Tayloristic organization and a more holistic organization that are focusing on coordination, integration of jobs, and multifaceted work. Project success requires a focused focus on completing the project and managing the job appropriately. Appropriate project management is important for successful implementation and covering several areas. Most of the construction companies have recently worked to increase the climate of confidence in the company to improve employees' performance. The concept of trust climate became well-known by Lewin and his colleagues in the late (1930s)[1]. The climate of confidence can be explained as an important attribute for the corporation environment by which an employee can perform is his/her duties which are based on a subjective assessment of his/her work environment [2]. The need for confidence between workers and their coworkers is essential because it influences the workforce's performance [3]. The climate of confidence is an important element to affect employee performance in the workplace. Alzahrani\& Emsley (2013) state that trust contributes to improve employees' performance "They say that trust among the member of the association benefits employees' performance". According to Kerzner, (2013)trust can be regarded as a special feature of organizing climate, reflecting a general and diffusive evaluation for the trustworthiness of the environment in which the employees can perform their duties. This study explains the role of the employees on their job regarding trust climate that is vital, since their performance will be excellent if they feel safe. Also, this study examines the relationship between employee's performance, effective team building and the strength of trust within the constructions companies[4].

\section{Literature review}

Continued research has been undertaken on the various dimensions especially the impact on project performance. Different variables are identified which are considered to be responsible for project complexity (project scale, factors of contingency, technological innovation, diversity of tasks, and rapid changes). The impact on the project performance has been analyzed[5]. New insights on project performance evaluation and discernment have been provided in another field of research depending on contingency theory. Contingency theory is recognized as one of the most important theories for project understanding, formulation, and management [6]. A review of research conducted by different researchers shows that in private and public sector organizations employee performance depends on variables, such as, trust and coordination[7].So that , the employees' performance is important for improving the performance of projects[8].

\subsection{Team members}

Cohen and Bailey (1997) describe the team as an integrated group of employees who are accounted for the results. Team members work together, show skills, work on helpful feedback and ease disputes between people [9]. Team dynamics is an important factor in ensuring smooth business management, particularly as a technology develops quickly. In their research, Pfaff and Huddleston (2003) indicate that teams are considered as key to various types of enterprises[10].

\subsection{Trust}

Trust is multidimensional, versatile, and includes interpersonal and impersonal confidence[11]. Greenwood and Van Buren, III (2010) have also studied that show the need to f explore further organizational credibility as a result of expectations, uprightness, and kindness[12]. Deep confidence is generated by team members who are highly dependent on the competencies and competencies of the members[13]. Developing trust between team members creates distinctive characteristics and commendable employee organization. Greenwood and Van Burenlll (2010) have showed that team performance and trust are positively related. Trust also outlines the team 
working behavior context, increases the productivity of the company, and the employee output in turn. The employee is individually responsible for the increase of trust in the company, butin turn the company is responsible for creating a congenial and trust-oriented climate [11]. Researches who build the projects of trust highlight the importance of first physical conferences , and the understanding of each other's motivational dynamics. Mortensen and O'Learys' (2012) findings have confirmed the effectiveness of several physical meetings during normal timeframes and after gaps[14][15].

\subsection{Trust among Team Members}

Trust among team members has a direct influence on the way tension and responsiveness come about due to a certain faith or a lack of self-confidence [16]. One's faith leads to achievements, motivations complete physical and mental goodness [17]. Sahertian and Soetjipto (2011) claim that automaticity has a significant impact on the work that is assigned to them, the capacity to meet their goals, a deeper focus, and a high degree of absorption from their employees. Furthermore, if employees within and outside a company have confidence, it would improve the employees' capacity [18].This means that trust must be established between the company and its members. If the employees' feelings lack of confidence in the company, this will result an increased costs of the company, a lack of work for the employees, lack of commitment, refusal to offer services against job responsibility, strikes and conflicts, a lack of interest, a decline in inspiration and innovation, a lack of internal collaboration that led to problems in the workplace strategy [18].This in fact demonstrates that the confidence climate of the organization is a key factor in the employees' performance. So, a reliable manager can encourage the employees to achieve organizing objectives. The trust and the performance of our employees are strongly linked., since organization calls for the environment of confidence especially the environment under which the employees see, observe and gain experience at the workplace and the conditions that support reward and strengthen less or more anticipated behaviors[19].Different trust theories have been suggested in which Whitener (2001)has presented social trust, the theory that shows that trust is known through sharing mutual benefit between the parties. This means that mutual sharing and benefits build confidence among employees within the organization. This study, therefore, considers the climate of trust as an independent variable[19].

\subsection{The Employees' Job Performance}

The organization's success depends on the employees' job performance, but it is unfair to assess the organizational performance as a combination of the total performance of the individuals. The employees' attitudes and satisfaction in many situations usually have a strong impact on the results of the behavior. So, there are however cases when external variables, situations, and the context intercept performance[20].Bakotic(2016) worthily has described the achievement of certain tasks as per previously determined standards of completeness, completeness, speed, cost[21]. In addition, the effective production and the efficient use of technology can demonstrate the employees' performance. Research's on different backgrounds predicting employment performance, specifically cognitive ability and personality have been done[22].Dessler(2011) helps to analyze the role of organizational confidence in promoting the performance of employees in public sector organizations. The relationship between the trust of employees and the morale of employees is strongly explained in this study. The morale of employees is strongly connected with the confidence of the organization. The morality of the employees is based on the trust and environment of the companies, while the communication gap can affect he employee performance as well as the organizational goals.

\subsection{The Employees' Performance}

Mwita (2000) has defined that the performance of the employees as the key factors of the multidimensional aspects that can be linked to the goals of the company[23]. The real performance of the employees can measure the organizational productivity and efficiency at work [23]. 
Performance can also be explained by the fact that he employees can perform their jobs discretion, assignment, or task according to certain organization rules and policies. The performance of the employees mainly depends on different aspects such as the assessment of performance, salary, confidence, motivation, work fulfillment, compensation, training and development, organizational structure, coaching, and so on [22]. In their study, Dyer and Holder (1988)have described a high level of training and coaching that is promoted in the company by the employees. The training program of employees, therefore, demonstrates that the management of companies is concerned with them and wanted to promote the skills and knowledge of their jobs. Training programs give employees the ability to influence the employees' performance. Therefore ,theemployees' performance can be defined as the typical level of performance that an employee (employee) normally performs so as to perform a role in his or her job. The productivity of employees is shown against the description of their jobs[21].

\subsection{The Relationship between The Employees' Performance and Job Performance}

The performance of the employees is related to the job performance which is defined as the final productivity of the employees' achievements by changing their interests and skills[24]. The employees' performance is the identification and participation of an individual (employee) in a specific organizational task. The employees' performance is the name of the employees' commitment to the organization, which Poteret al. (1974) say that it includes a long-standing desire to work in the organization; an enthusiastic commitment to their intentions, and the commitment to accept their organizational goals and tasks. The effectiveness of the employees against their jobs can be defined as the performance of the employee[25]. Hughes (2007)has explained that the quality of working places has an impact on the attitude of the employees which in turn increase their productivity. In addition, he has examined different industries on a multifaceted basis. The employees' performance is related to the effectiveness of the employees" against their task and assignment (job performance).According to Yang and Mossholder (2010)the report recommends certain facts since the employees may vary in terms of the capacity and skills in the field of work. has productivity of an employee can differ in the same working environment[26].

\subsection{The Measure of Trust}

Neal and Griffen (2002) have shown that the confidence can be measured by the conduct and attitude of the organizations[27]. Those working methods and processes behind the relationship remain unclear, even as they relate to the climate of the confidence and the achievements of the employees [26].McAllister (1995) explains two distinct dimensions of interpersonal trust: the first part comprises the cognitive, and the second part is the effective ones. The cognitive elements of the trust are problems such as integrity, reliability, and honesty of a person[28]. On the other side, the affecting form of faith is a relationship between the individuals who can influence the individual, elaborate their opinions concerning the well-being and prosperity of the truster. The first part shows overall the employees' performance of the measurement and evaluation. The second part explains how high-ranking and subordinate people relate to the organizations of human resources policies .Robert (2009)has found that the employees' trust can be linked to corporate the employment psychologically. When this relationship is strengthened the employer's commitment to the company's employees can be guaranteed. Three of the trustee's sensitivity, Hwee and Augustine (2009), are defined as experiences of confidence in coworkers, which include ability, generosity, and integrity. Benevolence and integrity are related positively and are important to the employees' confidence and to their ability in order to react to their working environment. The trust climate can be defined operationally as how the employees know the feature and understand the well-being of their organizational environment. View of the climate of confidence is linked to the performance of the employees. If the employees have confidence in the business environment, they will play their role better and more efficiently. The trust climate defines the environment of the organization that builds trust between its staff[28]. The following model is developed which isbased 
on a thorough literature review. The framework is based on the hypothesis that confidence will always favor the success of an organization. As a result, it also assumes that the employees will feel strong, positive and will voluntarily support the organization that they belong to, which in turn has resulted to increase the production efficiency and project success[26].So, the research model concludes that:

Teamwork efficacy has a significant positive relationship with trust.

The employees' performance has a significant positive relationship with trust.

Trust has a significant positive relationship with Employee Job Performance.

The employees' job performance has a significant positive relationship with increase productivity, customer satisfaction, implement the right strategy.

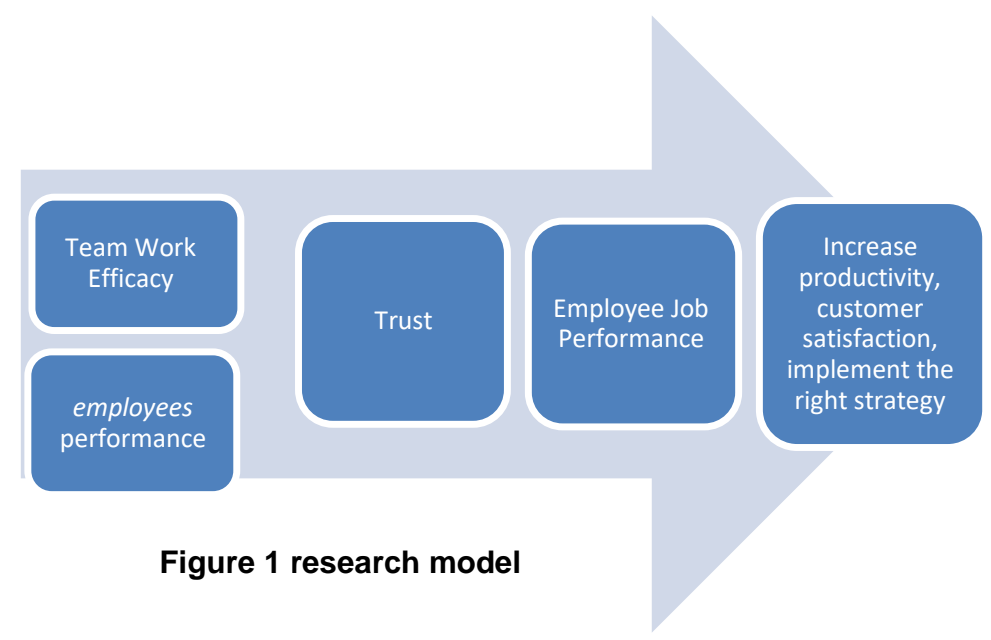

\section{Problem Statement}

Civil engineering projects in Iraq as having low construction quality. The findings of a quality study carried out by the International Federation of Engineers-Conseils on construction clearly shows that the building quality failure is a global concern [15]. Projects are temporary organizations, established to achieve desired goals and objectives [7], resulting in project teams being also temporary, redundant or reassigned after the completion of the project. A major drawback in temporary organizations is that project teams know that their contribution is only required for a limited period of time, This leads to a lack of trust among the project members, which negatively affects the performance of the project[29]. This research will confirm the importance of trust in the success of projects.

\section{Methodology}

The unit of analysis for this study is private and public sector projects in Iraq. This study is aimed to identify the relationship between trust teamwork efficacy and the employees' performance in private and public sector projects. This study is focused mainly on the workers and employees in projects because they are the best judges to assess the environment of the companies. The employees' responses on the climatic performance companies are collected via a self-administration questionnaire. The study is inherently descriptive which include(250)questionnaires Which are circulated and we have received (140)complete responses out of it representing a response rate of $(55 \%)$. The average age of the respondents is between (30-50)years while (25\%)is over (50)years, with an average experience of (10-5), over (15) years sequentially. (30\%)percentage of the respondents held Mid School degree and (25\%)a graduate degree and $(35 \%)$ held postgraduate qualifications such as M.B.A., Ph.D., and other post- 
graduation courses. (45\%) of the respondents are females and (55\%) are males. SPSS (20.0) is used to analyze these relationships.

\section{The Results and Discussions}

The regression analysis is used to test the relationship between the independent variable (trust) and dependent variable (employee performance and teamwork).First , have to check the correlation among the variables the correlation between the trust and employees' performance which is $(0.931)$ have a significant positive correlation, while $(0.896)$ of the correlation is between the trust and teamwork. Finally ,the correlation is (0.951) between the employees' performance and the teamwork. The relationship between effectiveness and the employees' performance has been checked at first. The relationship is significant with a regression coefficient value of $(0.586)$ which means that teamwork the efficacy and performance of the employees have a significant relationship. Then, the relation between trust and the employees' performance is examined. The regression coefficient value is $\left(0.612^{\star *}\right)$, so the job performance has a significant association with trust. Finally, the teamwork efficacy and trust relationship are computed. The relationship is significant with a regression coefficient value of $\left(0.653^{* *}\right)$. The primary observationhas explained that if the employees experience safety, psychological safety, and coordination between themselves, they are better placed to compare employees who are stressed. This study also shows that mental fulfillment and the respect for workers at work can increase the productive level of workers to achieve the goals of the organization.

\section{Conclusion}

Trust between team members is established when they trust each other's skills. It is the confidence that encourages distinctive qualifications and interconnections and interdependence between employees. The research shows that the relationship between the team performance and trust is significantly positive. Confidence creates a competency dimension in teamwork, a synergistic environment and increases the employees' productivity. Trust is the main task of the employees' foundation and growth. However, it is the only responsibility of managing the company so as to design and promote a friendly and credible environment for the executive teams. Because of deep partnership and the sense of interdependence, even brilliant executive teams survive. Furthermore, some factors such as low errors, have improved the customer satisfaction and the quality of the production which are examined for the team efficiency. In this study, it is clear that the importance of trust in workplaces is known to most of the employees." The following recommendations for future researches are practically based on the findings. In order for the organization to be more effective, authorities in this regard need to recognize the importance of confidence. The organization should realize the need for the climate of trust to build a long-term strategic objective for companies. construction companies owners should review the policy on their employees' trust. 


\section{References}

K. Lewin, R. Lippitt, and R. K. White, "Patterns of aggressive behavior in experimentally created 'social climates,"' J. Soc. Psychol., vol. 10, no. 2, pp. 269-299, 1939.

R. D. Costigan, S. S. liter, and J. J. Berman, "A multi-dimensional study of trust in organizations," J. Manag. issues, pp. 303-317, 1998.

R. C. Mayer, J. H. Davis, and F. D. Schoorman, "An integrative model of organizational trust," Acad. Manag. Rev., vol. 20, no. 3, pp. 709-734, 1995.

R. Hooijberg, N. Lane, and A. Diversé, "Leader effectiveness and integrity: Wishful thinking?," Int. J. Organ. Anal., 2010.

L. M. Cobos, C. Mejia, A. B. Ozturk, and Y. Wang, "A technology adoption and implementation process in an independent hotel chain," Int. J. Hosp. Manag., vol. 57, pp. 93-105, 2016.

Hanisch and A. Wald, "Effects of complexity on the success of temporary organizations: Relationship quality and transparency as substitutes for formal coordination mechanisms," Scand. J. Manag., vol. 30, no. 2, pp. 197-213, 2014.

D. B. Ramsden et al., "Human neuronal uncoupling proteins 4 and 5 (UCP4 and UCP5): structural properties, regulation, and physiological role in protection against oxidative stress and mitochondrial dysfunction," Brain Behav., vol. 2, no. 4, pp. 468-478, 2012.

S. Ruohomaa and L. Kutvonen, "Trust management survey," in International Conference on Trust Management, 2005, pp. 77-92.

P. J. Sloane, M. K. Jones, R. J. Jones, and P. L. Latreille, "Training, job satisfaction and establishment performance," 2007.

Y. Zhang, J. Ma, C. Pan, and R. Chang, "Effects of automation trust in drivers' visual distraction during automation," PLoS One, vol. 16, no. 9, p. e0257201, 2021.

M. Blaze, J. Feigenbaum, and A. D. Keromytis, "KeyNote: Trust management for public-key infrastructures," in International Workshop on Security Protocols, 1998, pp. 59-63.

M. Greenwood and H. J. Van Buren III, "Trust and stakeholder theory: Trustworthiness in the organisation-stakeholder relationship," J. Bus. ethics, vol. 95, no. 3, pp. 425-438, 2010.

M. Vanhala, K. Puumalainen, and K. Blomqvist, "Impersonal trust: The development of the construct and the scale," Pers. Rev., 2011.

A. K. Abdulkareem and R. M. Ramli, "Does trust in e-government influence the performance of egovernment? An integration of information system success model and public value theory," Transform. Gov. People, Process Policy, 2021.

J. Vrchota, P. Řehoř, M. Mařiková, and M. Pech, "Critical success factors of the project management in relation to industry 4.0 for sustainability of projects," Sustainability, vol. 13, no. 1, p. 281, 2021.

T. Hicks and M. McFrazier, College student self-efficacy research studies. University Press of America, 2014.

P. K. Chathoth, B. Mak, V. Jauhari, and K. Manaktola, "Employees' perceptions of organizational trust and service climate: A structural model combining their effects on employee satisfaction," J. Hosp. Tour. Res., vol. 31, no. 3, pp. 338-357, 2007.

F. F. Khiavi, K. Shakhi, R. Dehghani, and M. Zahiri, "The correlation between organizational justice and trust among employees of rehabilitation clinics in hospitals of Ahvaz, Iran," Electron. physician, vol. 8, no. 2, p. 1904, 2016.

A. Chitsaz-Isfahani and H. R. Boustani, "Effects of talent management on employees retention: The mediate effect of organizational trust," Int. J. Acad. Res. Econ. Manag. Sci., vol. 3, no. 5, p. 114, 2014.

S. A. I. Mahmood, "Impact of Climate Change in Bangladesh: The Role of Public Administration and Governments Integrity.," J. Ecol. Nat. Environ., vol. 4, no. 8, pp. 223-240, 2012. 
D. Bakotić, "Relationship between job satisfaction and organisational performance," Econ. Res. istraživanja, vol. 29, no. 1, pp. 118-130, 2016.

B. Radošević-Vidaček, A. Košćec, and M. Bakotić, "Parents working non-standard schedules and schools operating in two shifts: effects on sleep and daytime functioning of adolescents," in Social and Family Issues in Shift Work and Non Standard Working Hours, Springer, 2016, pp. 109-136.

J. I. Mwita, "Performance management model: A systems-based approach to public service quality," Int. J. Public Sect. Manag., 2000.

E. Jones, The European miracle: environments, economies and geopolitics in the history of Europe and Asia. Cambridge University Press, 2003.

D. M. Medly and D. N. Shannon, "Teacher Education. The International Encyclopedia of Education System," Oxford, vol. 10, no. 2, pp. 6015-6020, 1994.

J. Yang and K. W. Mossholder, "Examining the effects of trust in leaders: A bases-and-foci approach," Leadersh. Q., vol. 21, no. 1, pp. 50-63, 2010.

S. R. Kessler, P. E. Spector, C.-H. Chang, and A. D. Parr, "Organizational violence and aggression: Development of the three-factor Violence Climate Survey," Work Stress, vol. 22, no. 2, pp. 108-124, 2008.

D. J. McAllister, "Affect-and cognition-based trust as foundations for interpersonal cooperation in organizations," Acad. Manag. J., vol. 38, no. 1, pp. 24-59, 1995.

S. Desposato, T. Levinson, and N. Weller, "The impact of group collaboration and performance on interpersonal trust and cooperation," J. Artic. Support Null Hypothesis, vol. 18, no. 1, p. 2, 2021. 